\title{
Antioxidant Responses Induced by UVB Radiation in Deschampsia antarctica Desv.
}

\author{
Hans Köhler, Rodrigo A. Contreras, Marisol Pizarro, Rodrigo Cortés-Antíquera and \\ Gustavo E. Zúñiga*
}

Laboratorio de Fisiología y Biotecnología Vegetal, Departamento de Biología, Facultad de Química y Biología - Centro para el Desarrollo de la Nanociencia y Nanotecnología, Universidad de Santiago de Chile, Santiago, Chile

OPEN ACCESS

Edited by:

Zhulong Chan,

Huazhong Agricultural University,

China

Reviewed by:

Hyoungseok Lee,

Korea Polar Research Institute,

South Korea

Erik T. Nilsen,

Virginia Tech, United States

*Correspondence:

Gustavo E. Zúñiga

gustavo.zuniga@usach.cl

Specialty section:

This article was submitted to

Plant Abiotic Stress,

a section of the journal

Frontiers in Plant Science

Received: 06 December 2016

Accepted: 16 May 2017

Published: 31 May 2017

Citation:

Köhler $H$, Contreras RA, Pizarro $M$,

Cortés-Antíquera R and Zúñiga GE

(2017) Antioxidant Responses

Induced by UVB Radiation

in Deschampsia antarctica Desv.

Front. Plant Sci. 8:921.

doi: 10.3389/fpls.2017.00921
Deschampsia antarctica Desv. is one of two vascular plants that live in the Maritime Antarctic Territory and is exposed to high levels of ultraviolet-B (UVB) radiation. In this work, antioxidant physiology of $D$. antarctica was studied in response to UVB induced oxidative changes. Samples were collected from Antarctica and maintained in vitro culture during 2 years. Plants were sub-cultured in a hydroponic system and exposed to $21.4 \mathrm{~kJ} \mathrm{~m}^{-2}$ day $^{-1}$, emulating summer Antarctic conditions. Results showed rapid and significant increases in reactive oxygen species (ROS) at $3 \mathrm{~h}$, which rapidly decreased. No dramatic changes were observed in photosynthetic efficiency, chlorophyll content, and level of thiobarbituric acid reactive species (MDA). The enzymatic (superoxide dismutase, SOD and total peroxidases, POD) and non-enzymatic antioxidant activity (total phenolic) increased significantly in response to UVB treatment. These findings suggest that tolerance of $D$. antarctica to UVB radiation could be attributed to its ability to activate both enzymatic and non-enzymatic antioxidant systems.

Keywords: Deschampsia Antarctica Desv., Poaceae, Antarctica, UVB radiation, antioxidant responses

\section{INTRODUCTION}

Since the 1980s, stratospheric ozone has been catalytically broken down by the introduction of man-made chlorofluorocarbon compounds into the atmosphere, resulting in significantly decreased ozone levels (Solomon, 2004; Shanklin, 2010). The largest extent of this depletion occurs during the austral spring when an ozone hole forms above Antarctica. This consequently decreases the shielding effect of the ozone layer in this region which results in an increase in ultravioletB radiation (UVB; 280-315 nm) reaching the surface of Antarctica (Kerr and McElroy, 1993; Ruhland and Day, 2000). Although ozone depletion models predict slow Antarctic ozone recovery, the seasonal and long-term levels of damaging UVB radiation are likely to remain high for decades to come (Kramarova et al., 2014; Solomon et al., 2016).

The most common effects of UVB radiation on plant physiology are reduced biomass (Tevini and Teramura, 1989), alteration of the cuticle and the epidermis (Tevini and Steinmüller, 1987), abnormal growth and impaired photosynthesis (Teramura et al., 1990; Teramura and Sullivan, 1994), and damage to the photosystem I (PSI) and photosystem II (PSII) proteins (Pang and Hays, 1991; Liu et al., 2013). At the cellular level, UVB radiation initially causes an increase in reactive oxygen species (ROS) levels, which subsequently oxidizes proteins, lipids, and other biomolecules, thus, compromising the functionality and integrity of enzymes and cell membranes (Kochevar, 1990; Robson et al., 2015). Two ROS 
scavenging mechanisms can control this oxidative stress in plants: enzymatic and non-enzymatic antioxidant systems (Mittler, 2002).

Firstly, antioxidant enzymes act constantly to control and detoxify ROS, increasing their activity in response to high levels of oxidative species (Mittler, 2002). An important antioxidant enzyme is the superoxide dismutase (SOD, EC 1.15.1.1), a metalloenzyme that plays a key role in protecting molecules in plants from oxidation damage. SOD functions by dismutating the superoxide ion $\left(\mathrm{O}_{2}{ }^{-}\right)$into less harmful hydrogen peroxide $\left(\mathrm{H}_{2} \mathrm{O}_{2}\right)$, which can then be converted to $\mathrm{H}_{2} \mathrm{O}$ by ascorbate peroxidase (APX, EC 1.11.1.11), total peroxidases (POD) and catalase (CAT, EC 1.11.1.6) enzymes. These enzymes work together in the regulation of ROS levels through their role in the water-water cycle and water-ascorbate-glutathione cycle (Mittler, 2002).

Secondly, detoxification and regulation of ROS through non-enzymatic mechanisms involve secondary metabolites, compounds that plants produce in response to several environmental conditions (Dixon and Paiva, 1995). These metabolites include types of phenolic compounds, flavonoids, and hydroxycinnamic acid esters; most of these compounds have antioxidant activity, i.e., the ability to scavenge free radicals. These secondary metabolites are not only essential for their antioxidant properties, because they also directly absorb UVB wavelengths, acting potentially as sunscreens forming part of a common protection mechanism in plants (Frohnmeyer and Staiger, 2003; Petersen et al., 2010). The biosynthesis of secondary metabolites is highly regulated by the phenylalanine ammonia lyase (PAL) (E.C. 4.1.1.5) (Winkel-Shirley, 2002), a key enzyme in the response against adverse environmental conditions such as UVB radiation (Kalbin et al., 2001). An increase in UVB light enhances PAL activity which increases the production of phenolic metabolites that directly and indirectly protect against UVB-induced damage (Hideg et al., 2013).

Fluctuations in UVB radiation represent an ongoing stress to plants. For example, in Tierra del Fuego, in southern South America, native plants show limited or no acclimation responses to environmental UVB radiation, such as an increasing of sunscreen compounds levels or an enhanced DNA repair capacity (Sancar and Sancar, 1988; Rousseaux et al., 1999). In subAntarctic regions, the impact of short periods of increased UVB radiation is related to an increase of DNA damage levels in leaf tissue in the native herb Gunnera magellanica (Rousseaux et al., 2004).

Antarctica represents an extreme environment, the presence of high soil salinity, low water potential, low temperatures, and drastic changes in white light and UVB radiation levels in the transition from winter (absence of light) to springsummer (high light intensities). It has been reported that extreme shifts in UVB light occur not only over decades, but there are also annual, monthly, and daily variations that induce significant changes at different levels in Antarctic plants (Xiong and Day, 2001; Robinson et al., 2003). During the summer growing period (November to February), the day length is approximately $20 \mathrm{~h}$, and the white light irradiation in the maritime Antarctic can exceed levels of $1600 \mu \mathrm{mol} \mathrm{m}^{-2} \mathrm{~s}^{-1}$
(Xiong and Day, 2001; Rozema et al., 2002), so these plants are subjected to contrasting environmental variations daily.

Daily and seasonal variation in UVB radiation induces antioxidant responses, including increases in protective secondary metabolite synthesis, in Antarctic vegetation. Despite extreme conditions, $D$. antarctica is the most successful angiosperm that has colonized the maritime Antarctic territory (Robinson et al., 2003; Hyoungseok et al., 2008). It has been suggested that tolerance of $D$. antarctica to changing levels of UVB radiation in situ is due to its synthesis and storage of phenolic-type molecules that play an important role in protecting biomolecules (Xiong and Day, 2001; van de Staaij et al., 2002). This response was observed when this Antarctic hairgrass was exposed to UVB radiation under controlled conditions in a photobioreactor (Sequeida et al., 2012).

Despite the relevant role of antioxidant responses in its UVB radiation tolerance of $D$. antarctica, the specific antioxidant mechanisms involved in its capacity to survive in high UVB light environments remain uncharacterized. Therefore, the aims of this work were to determine the effect of UVB radiation on various physiological parameters and to monitor several enzymatic and non-enzymatic antioxidant responses of D. antarctica exposed to daily UVB radiation doses equivalent to Antarctic conditions. We hypothesized that $D$. antarctica utilizes many efficient antioxidant mechanisms in order to survive under elevated UVB radiation due to ozone depletion.

\section{MATERIALS AND METHODS}

\section{Plant Material}

Whole plants of $D$. antarctica were collected from King George Island, South Shetland Islands $\left(62^{\circ} 814^{\prime} \mathrm{S} ; 58^{\circ} 848^{\prime} \mathrm{W}\right)$ and cultured in vitro (Zamora et al., 2010). Plants were cultured in a growth chamber $\left(16 \pm 2^{\circ} \mathrm{C}, 16 / 8\right.$-h light/dark period) under a low UVB radiation dose $\left(1.7 \mathrm{~kJ} \mathrm{~m}^{-2} \mathrm{~d}^{-1}\right.$, growth chamber) (Figure 1). Plantlets were acclimated in an ex vitro culture in hydroponic conditions using Hoagland No. 2 solution (Hoagland and Arnon, 1950) in volcanic pearl for 2 weeks under the low UVB radiation dose described above. Afterward, cultured plants underwent a UVB light treatment that was performed using mercury lamps (Supplementary Figure 1) and a total daily dose of $21.4 \mathrm{~kJ} \mathrm{~m}^{-2} \mathrm{~d}^{-1}$ (Figure 1), similar to field UVB doses measured in King George Island (unpublished data). Control plants were exposed to a white lamp with a residual UVB radiation dose of $1.7 \mathrm{~kJ} \mathrm{~m}^{-2} \mathrm{~d}^{-1}$. All control and UVB treated samples were collected and maintained at $-80^{\circ} \mathrm{C}$ before processing.

\section{Total Reactive Oxygen Species (ROS)}

Total ROS was analyzed using fluorimetric quantitation of dichlorodihydrofluorescein-diacetate (DCDHF-DA) that was oxidized by ROS. Fresh plant tissue $(100 \mathrm{mg})$ was incubated in $1 \mathrm{~mL}$ of $10 \mu \mathrm{M}$ of DCDHF-DA in Tris- $\mathrm{HCl}(50 \mathrm{mM}, \mathrm{pH}$ 8.0) for $1 \mathrm{~h}$ at room temperature, then the tissue was washed with $50 \mathrm{mM}$ EDTA to remove the incubation solution and ground to a fine powder as above and extracted in $1 \mathrm{~mL}$ of 


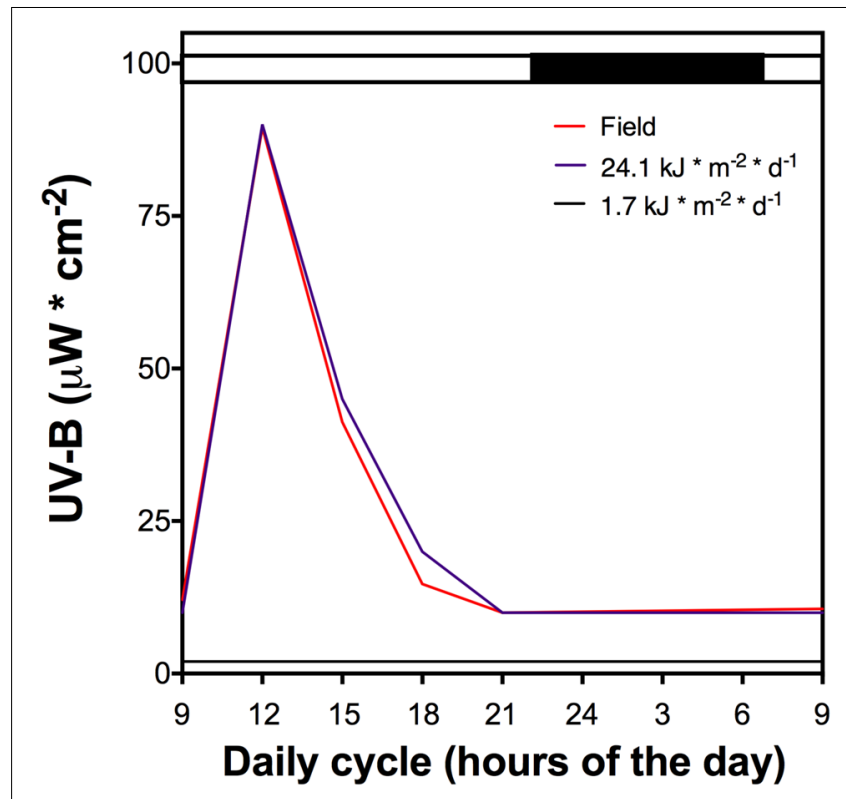

FIGURE 1 | The UV-B light cycle that the cultured $D$. antarctica plants were exposed, purple line represents $21.4 \mathrm{~kJ} \mathrm{~m}^{-2} \mathrm{~d}^{-1}$ dose, black line the control $\left(1.7 \mathrm{~kJ} \mathrm{~m}^{-2} \mathrm{~d}^{-1}\right)$ and red line UV-B data recorded in field conditions. Light period is indicated by a white bar and darkness by a black bar above the figure. The dark period shows a low UV-B radiation dose.
Tris-HCl (50 mM, pH 8.0). The supernatant obtained from this mixture after centrifugation at 10,000 rpm for $10 \mathrm{~min}$ was filtered in Miracloth. The fluorescence (488 nm excitation wavelength, $535 \mathrm{~nm}$ emission wavelength; Perkin-Elmer, LS4) was determined for the filtered supernatant (Ross et al., 2008).

\section{Membrane Peroxidation}

Fresh tissue $(50 \mathrm{mg}$ ) was ground to a powder as above and suspended in $1 \mathrm{~mL}$ of $1 \%$ of trichloroacetic acid (TCA). The resultant mixture was centrifuged at $8,000 \mathrm{rpm}$ for $5 \mathrm{~min}$. To the supernatant $(250 \mu \mathrm{L}), 1 \mathrm{~mL}$ of $0.5 \%$ of thiobarbituric acid in $20 \%$ TCA was added and the mixture was boiled for $30 \mathrm{~min}$. This was then allowed to cool to room temperature and the adduct formed by TBA-malondialdehyde (MDA) was quantified at 532 and $600 \mathrm{~nm}$ using $\varepsilon=155 \mathrm{mM}^{-1} \mathrm{~cm}^{-1}$ (Ederli et al., 2004).

\section{Photosynthetic Pigments (Chl-a/b)}

The total content of Chl- $a$ and Chl- $b$ was determined using fresh tissue $(100 \mathrm{mg})$ that was ground to a powder using liquid nitrogen and a mortar and pestle before extraction in acetone $(10 \mathrm{~mL})$. The mixture was centrifuged at 8,000 rpm (Biofuge Fresco, Heraeus Inst., Hanau, Germany) for $15 \mathrm{~min}$ at $4^{\circ} \mathrm{C}$ and the absorbance of the supernatant at 649 and $665 \mathrm{~nm}$ was measured on a UVVis spectrophotometer (Agilent 8453, Santa Clara, CA, United States) (Lichtenthaler and Wellburn, 1983).

\section{Photosynthetic Efficiency}

A photosynthetic efficiency analyzer (PEA; Hansatech, Norfolk, United Kingdom) was used to measure photosynthetic efficiency. Etiolating clamps were placed on the leaves for $30 \mathrm{~min}$ and the variable and maximum fluorescence of PSII was measured. Results are expressed as Fv/Fm (PSII maximum efficiency).

\section{Antioxidant Enzymes Extraction}

Fresh tissue (100 mg) was ground to a fine powder and extracted in $1 \mathrm{~mL}$ of sodium phosphate buffer $(50 \mathrm{mM}, \mathrm{pH} 7.5)$. Mixture was centrifuged at $10,000 \mathrm{rpm}$ for $10 \mathrm{~min}$ at $4^{\circ} \mathrm{C}$. Supernatant was recovered and the concentration of the soluble proteins was determined according to Bradford methodology (Bradford, 1976) using bovine serum albumin (BSA) for the standard curve. This extract is referred to as the protein extract for the following enzyme activity assays.

\section{Superoxide Dismutase (SOD) Activity (EC 1.15.1.1)}

A reaction mixture was prepared using $600 \mu \mathrm{L}$ of sodium phosphate buffer (50 mM,pH 7.5), $10 \mu \mathrm{L}$ of $10 \mathrm{mM}$ EDTA, $100 \mu \mathrm{L}$ of $130 \mathrm{mM}$ methionine, $10 \mu \mathrm{L}$ of $2 \mathrm{mM}$ riboflavin, $200 \mu \mathrm{L}$ of $3 \mathrm{mM}$ of nitroblue tetrazolium in $70 \%$ dimethylformamide and $100 \mu \mathrm{L}$ of protein extract. The mixture was incubated under white light for $15 \mathrm{~min}$ at room temperature (a blank mixture was kept in the dark). Absorbance at $560 \mathrm{~nm}$ was determined where one enzymatic unit (EU) was considered to have the capacity to inhibit $50 \%$ of photochemical reduction of NBT (Beauchamp and Fridovich, 1971).

\section{Ascorbate Peroxidase (APX) Activity (EC 1.11.1.11)}

A reaction mixture that contained $935 \mu \mathrm{L}$ of sodium phosphate buffer ( $50 \mathrm{mM}, \mathrm{pH} 7.5$ ), $20 \mu \mathrm{L}$ of protein extract, $5 \mu \mathrm{L}$ of $100 \mathrm{vol}$. hydrogen peroxide and $40 \mu \mathrm{L}$ of $10 \mathrm{mM}$ sodium ascorbate was prepared. Absorbance at $290 \mathrm{~nm}$ was recorded after the reaction had proceeded for $1 \mathrm{~min}$ indicating APX activity in terms of ascorbate consumption. APX activity was calculated using molar extinction of ascorbate, $\varepsilon=2.8 \mathrm{mM}^{-1} \mathrm{~cm}^{-1}$ (Lima et al., 2002).

\section{Total Peroxidases (POD) Activity (EC 1.11.1.7)}

A reaction mixture that contained $980 \mu \mathrm{L}$ of sodium phosphate buffer $(50 \mathrm{mM}, \mathrm{pH} 7.5), 10 \mu \mathrm{L}$ of protein extract, $5 \mu \mathrm{L}$ of 100 vol. hydrogen peroxide and $5 \mu \mathrm{L}$ of guaiacol was prepared. Absorbance at $470 \mathrm{~nm}$ was recorded after a reaction time of $1 \mathrm{~min}$ indicating POD activity in terms of tetrahydroguaiacol (THG) formation. POD activity was calculated using molar extinction of THG, $\varepsilon=26.6 \mathrm{mM}^{-1} \mathrm{~cm}^{-1}$ (Zamora et al., 2010).

\section{Catalase (CAT) Activity (EC 1.11.1.6)}

A reaction mixture that contained $975 \mu \mathrm{L}$ of sodium phosphate buffer (50 mM, pH 7.5), $20 \mu \mathrm{L}$ of protein extract and $5 \mu \mathrm{L}$ of $100 \mathrm{vol}$. hydrogen peroxide was prepared. Absorbance at $240 \mathrm{~nm}$ was recorded after reaction time of 1 min indicating CAT activity in terms of hydrogen peroxide consumption. CAT activity was calculated using molar extinction of hydrogen peroxide, $\varepsilon=39.4 \mathrm{mM}^{-1} \mathrm{~cm}^{-1}$ (Lima et al., 2002). 


\section{Phenylalanine Ammonia Lyase (PAL) Activity (EC 4.3.1.24)}

Proteins were extracted from ground fresh tissue $(100 \mathrm{mg})$ using $\mathrm{x} \mathrm{mL}$ of $50 \mathrm{mM}$ of Tris- $\mathrm{HCl}(\mathrm{pH} 8.5)$ containing $14.4 \mathrm{mM}$ of 2-mercaptoethanol and 5\% PVPP-40. After the mixture was centrifuged at 11,000 rpm for $10 \mathrm{~min}$, total protein content of the supernatant was analyzed using the Bradford method (Bradford, 1976). To measure PAL activity, two different mixtures were prepared: one containing $2.5 \mathrm{~mL}$ of $0.2 \% \mathrm{~L}$-phe and $500 \mu \mathrm{L}$ of protein extract; and another containing $0.2 \% \mathrm{D}$-phe in Tris- $\mathrm{HCl}$ ( $\mathrm{pH}$ 8.5), which was used as the negative control. The sample and control mixtures were incubated at $38^{\circ} \mathrm{C}$ for $2 \mathrm{~h}$, allowing the reaction to proceed. After incubation, the trans-cinnamic acid product was detected at $290 \mathrm{~nm}$. The difference between L-phe and D-phe was used to calculate the activity (Pellegrini et al., 1994).

\section{Plant Hydroalcoholic Extracts}

A total of $100 \mathrm{mg}$ of fresh plant material was mixed with $1 \mathrm{~mL}$ of ethanol $(85 \% \mathrm{v} / \mathrm{v})$ and sonicated at $50-60 \mathrm{~Hz}$ for $2 \mathrm{~h}$ at $25^{\circ} \mathrm{C}$ according to the method previously described by Contreras et al. (2015). Extracts were filtered in a $0.45 \mu \mathrm{m}$ pore filter (Millipore, Billerica, MA, United States) and analyzed for total phenolic content.

\section{Total Phenolic Content}

The total phenolic content was determined using a modified Folin-Ciocalteu colorimetric method (Contreras et al., 2015). Plant hydroalcoholic extract $(40 \mu \mathrm{L})$ was added to $100 \mu \mathrm{L}$ of Folin-Ciocalteu's reagent and $560 \mu \mathrm{L}$ of deionized water and mixed. After $15 \mathrm{~min}$ at room temperature, the reaction was stopped by adding $300 \mu \mathrm{L}$ of $7 \%$ aqueous sodium carbonate to the mixture. The absorbance was measured at $660 \mathrm{~nm}$ on an Agilent 8453 UV-Vis spectrophotometer. The results were expressed in gallic acid (GA) equivalents per gram of DW.

\section{Non-enzymatic Antioxidant Scavenging Activity}

The 1,1-diphenyl-2-picrylhydrazyl (DPPH) free-radical scavenging assay was used to measure the capacity of nonenzyme compounds to scavenge free radicals (Naik et al., 2005). Plant hydroethanolic $(85 \%)$ extract $(100 \mu \mathrm{L})$ was added to $900 \mu \mathrm{L}$ of DPPH $\left(\mathrm{A}_{517}=0.75\right)$ and the absorbance at $517 \mathrm{~nm}$ was measured after a $5 \mathrm{~min}$ incubation at $37^{\circ} \mathrm{C}$. Antioxidant activity is expressed as percentage DPPH consumption where DPPH $\left(\mathrm{A}_{517}=0.75\right)$ was used as a control reference (Naik et al., 2005).

\section{The Antioxidant Activity Assay/Reducing Power Assay (FRAP)}

The antioxidant activity assay/reducing power assay (FRAP) was performed using the method described in Benzie and Strain (1999). Absorbance kinetics (4 min) were determined at $593 \mathrm{~nm}$ on a spectrophotometer. The results are expressed as Trolox equivalents (E-Trolox).

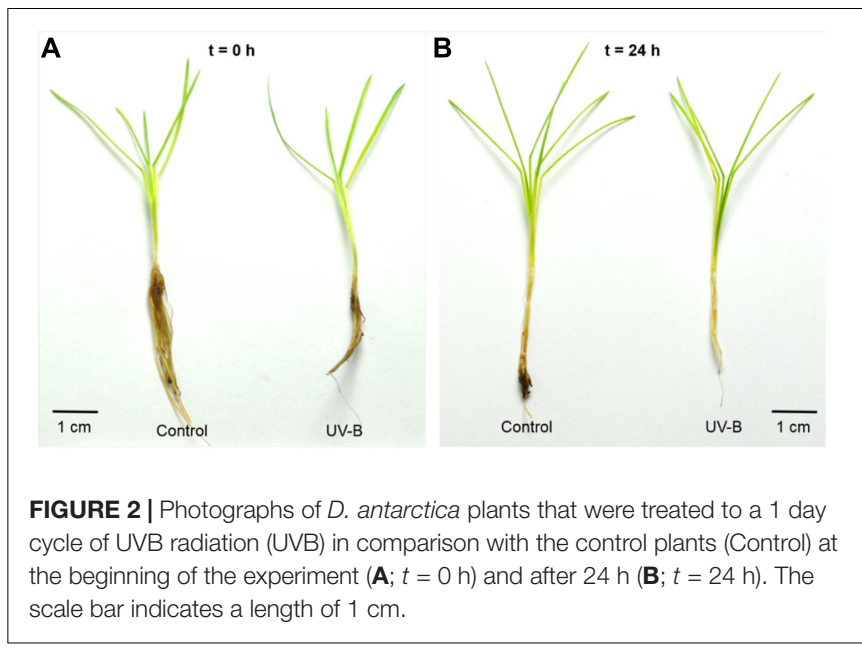

\section{Statistical Analysis}

All the experiments were performed in triplicates, for statistically significant differences we used two-way ANOVA with multiple comparisons. Post hoc analysis was performed using the Bonferroni's post-test $(P<0.05)$.

\section{RESULTS}

After a daily dose of UVB $\left(21.4 \mathrm{~kJ} \mathrm{~m}^{-2} \mathrm{~d}^{-1}\right), D$. antarctica plants showed a similar appearance compared to the control (Figure 2). However, there were biochemical and physiological differences found in response to UVB radiation (Figure 3). Total ROS content and membrane peroxidation showed a maximum peak of accumulation at $3 \mathrm{~h}$ of UVB exposure before gradually declining to initial levels over the next $12 \mathrm{~h}$ (Figure 3A). ROS levels in the control plants did not change significantly over the day experiment. Membrane peroxidation content remained consistently and significantly higher in the UVB treated plants compared with the control plants (Figure 3B). In contrast, the chlorophyll $a / b$ ratio presented a temporary decrease of $9.8 \%$ with respect to the control after $3 \mathrm{~h}$ of UVB exposure (Figure 3C). The PSII maximum efficiency was slightly affected by the treatment in values nearby to $5 \%$ (Figure 3D). These results suggest that $D$. antarctica may control ROS to maintain the cell function.

To evaluate the mechanisms involved in the ROS buffering, we analyzed the activity of both enzymatic and non-enzymatic antioxidant systems. At $3 \mathrm{~h}$ of UVB exposure, a peak in SOD activity associated with the ROS content peak was observed. Both of these parameters then decreased in a similar way (Figure 4A). APX activity also showed a slight increase at $3 \mathrm{~h}$ of treatment but this higher level was maintained until the end of the cycle (Figure 4B), similar to membrane peroxidation levels and loss of PSII maximum efficiency (Figures 3B,D). POD activity rapidly increased in the UVB treated plant in the first $3 \mathrm{~h}$ of UVB exposure reaching a level ten times than the control plants after $6 \mathrm{~h}$ (Figure 4C). Although CAT showed an upregulation in UVB treatment, the activity was more discrete compared with the 


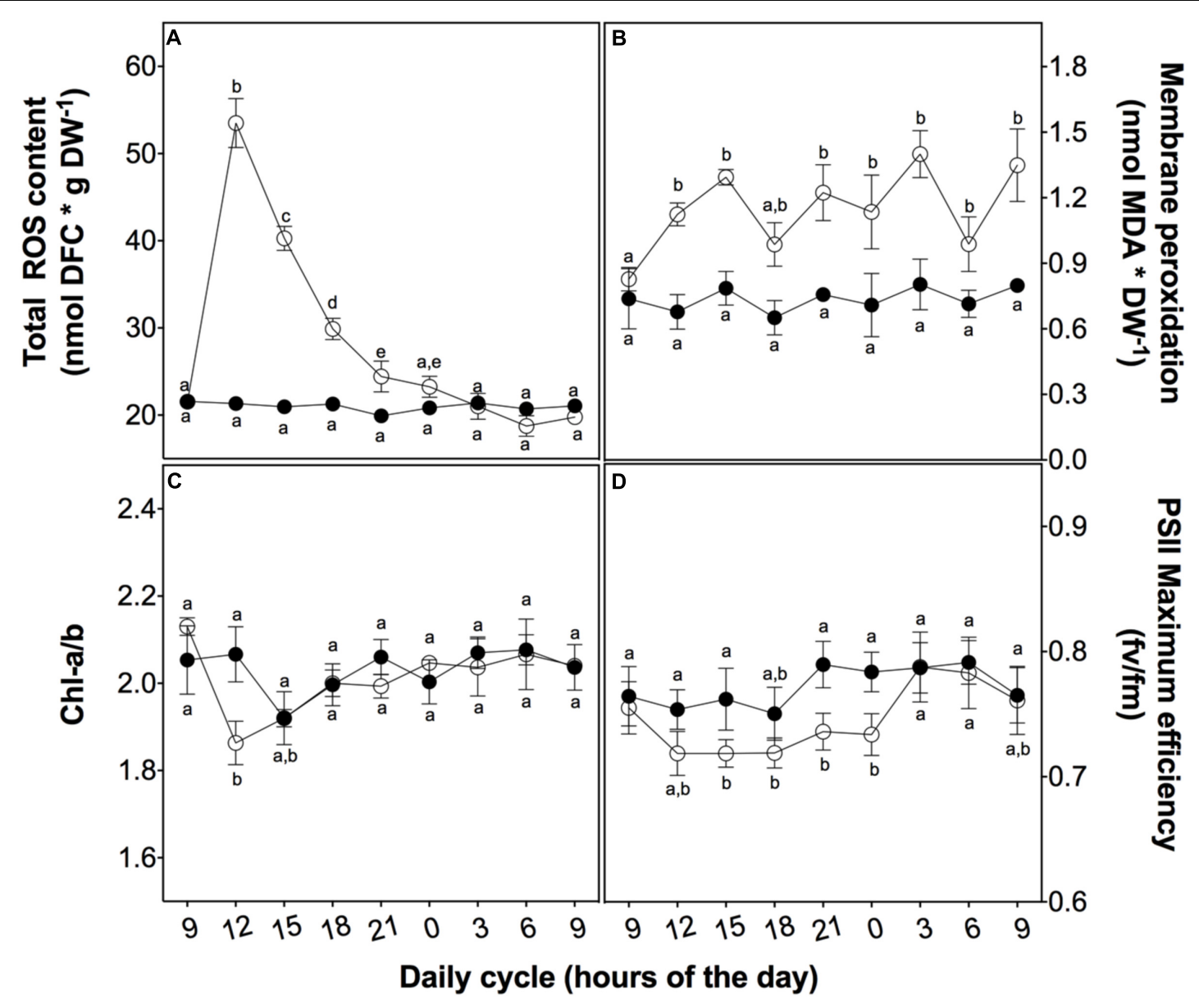

FIGURE 3 | Effect of UVB radiation on physiological parameters in D. antarctica plants grown ex vitro. (A) Total ROS content. (B) Membrane peroxidation (thiobarbituric acid reactive substances). (C) The ratio of chlorophyll a and $b$. (D) Photosynthetic efficiency of PSII. Open circles represent means ( \pm standard error of the mean; $N=3$ ) of plants that underwent the UVB treatment and closed circles represent the control means ( \pm standard error of the mean; $N=3$ ). Significant differences between treatments are indicated by letters $\left({ }^{*} P<0.05\right)$.

other antioxidant enzymes measured (Figure 4D). These results suggest that $\mathrm{POD}$ is the principal $\mathrm{H}_{2} \mathrm{O}_{2}$ scavenger enzyme.

To investigate the role of phenolic compounds as nonenzymatic antioxidants, we measured the total content of phenolic compounds and their antioxidant activity as a reductive power and free radical-scavenger (Figure 5). Firstly, the activity of the key enzyme of the phenylpropanoid metabolism, PAL, peaked at $3 \mathrm{~h}$ in treated plants (Figure 5A). This peak is likely associated with total phenolic content (Figure 5B), ROS levels (Figure 3A), and SOD and POD activities (Figures 4A,C), suggesting a complementary role of phenolic compounds as a $\mathrm{H}_{2} \mathrm{O}_{2}$ controller.

Secondly, to explain the role of phenolics, we evaluated the free radical-scavenging activity and the reducing power of $D$. antarctica secondary metabolites. DPPH-scavenging and reducing power (Figures 5C,D) showed a peak of activity at $3 \mathrm{~h}$, strictly related to other antioxidant parameters, such as those mentioned above, supporting the hypothesis of the ROS buffering role of phenolics.

\section{DISCUSSION}

Plants respond to UVB radiation through a series of strategies and mechanisms (Müller-Xing et al., 2014). Under UVB radiation, leaf morphology changes and presents a curly arrangement, but in this study $D$. antarctica leaves showed no apparent morphological damage when exposed to a daily UVB dose of $21.4 \mathrm{~kJ} \mathrm{~m}^{-2}$ day $^{-1}$. This lack of morphological changes monitored over a 24 -h period does not mean a lack of response against this condition (Rao et al., 1996).

Reactive oxygen species accumulation is largely described as a stress marker in aerobic organisms; in plants many authors have described its accumulation in response to environmental changes, including UVB radiation. Here, we show that total ROS levels in D. antarctica sharply increased after $3 \mathrm{~h}$ of UVB exposure and then gradually declined. We expected to observe an effect of this climax in ROS levels in the generation of lipoperoxides as membranes are one of the most susceptible targets to ROS accumulation. In the case of D. antarctica, 


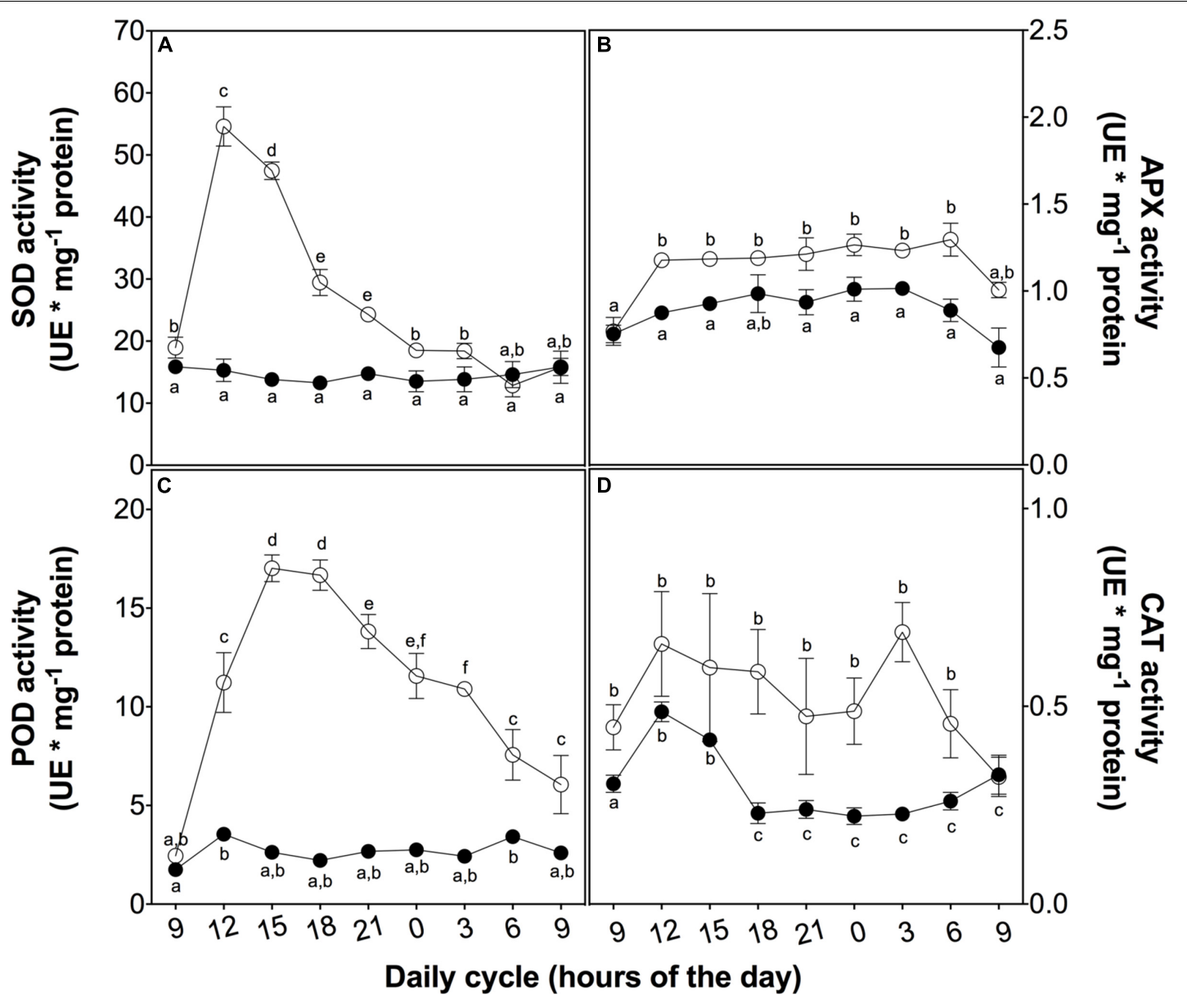

FIGURE 4 | Antioxidant enzyme activity in D. antarctica plants exposed to UVB radiation and control conditions. Superoxide dismutase activity (A), ascorbate peroxidase activity (B), the total activity of peroxidases $(\mathbf{C})$ and catalase activity $(\mathbf{D})$ is observed. Open circles represent means $( \pm$ standard error of the mean; $N=3$ ) of plants that underwent the UVB treatment and closed circles represent the control means ( \pm standard error of the mean; $N=3$ ). Significant differences between treatments are indicated by letters $\left({ }^{*} P<0.05\right)$.

significantly higher levels of lipoperoxides were found in the UVB treated plants, but these were quite low especially when compared with other plant species, such as rice (Du et al., 2010).

In contrast, the chlorophyll $a / b$ ratio showed a decrease in plants at $3 \mathrm{~h}$ of UVB exposure compared to the control plants. This observation was expected because pigments of the photosynthetic apparatus are negatively affected by UVB radiation (Jansen et al., 1998; Vass et al., 2005). Chlorophyll pigments and some proteins that are components of PSI and PSII are frequently oxidized through changes in light intensity (Von Wettstein et al., 1995; Chatterjee and Kundu, 2015). UVB light not only disturbs chlorophyll synthesis, it also affects photosynthetic efficiency of PSII (Edelman and Mattoo, 2008) and subsequently alters the photosynthetic efficiency (Heifetz et al., 1997).

Ultraviolet-B treated $D$. antarctica showed a discrete but significant decrease in $F \mathrm{v} / F \mathrm{~m}$, revealing a partial stress (a decrease of $5 \%$ relative to the control plants), and it recuperated to normal levels after $3 \mathrm{~h}$ in the dark, supporting the efficiency of stress responsive elements (Byun et al., 2015). This is probably because this particular Antarctic plant has developed several mechanisms to dissipate excess energy reaching chloroplasts (Ruhland and Day, 2000; Frohnmeyer and Staiger, 2003; Ruhland et al., 2005) Effects. D. antarctica has not shown signs of photoinhibition when exposed to bright light and neither have thermal deactivation mechanisms been detected (Pérez-Torres et al., 2007). No evidence of dramatic loss of photosynthetic efficiency was observed, suggesting that $D$. antarctica utilizes active response mechanisms that were previously unknown (Ruhland and Day, 2000; Pérez-Torres et al., 2007).

Controlling oxidative damage is a trait that depends on the plasticity of a species that allows a rapid response to environmental conditions (Smith, 1990; Tognetti et al., 2012). Our results show a plastic response of $D$. antarctica to a UVBinduced increase of ROS levels by initiating a series of enzymatic and non-enzymatic processes to prevent significant damage to plasma membranes or other organelles (Foyer and Noctor, 2005; 


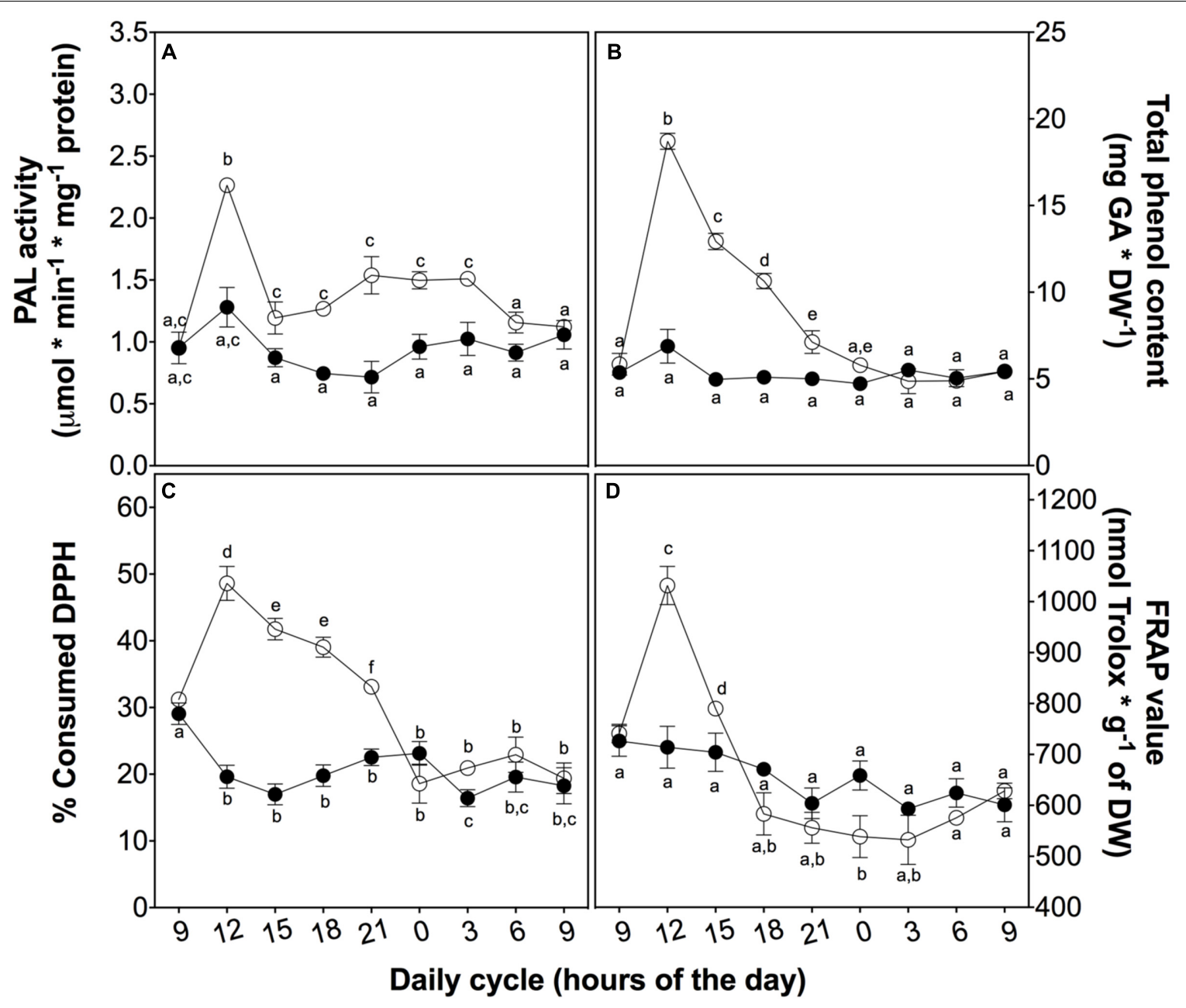

FIGURE 5 | Non-enzymatic antioxidant activity in D. antarctica plants exposed to UVB radiation and control conditions. PAL activity (A) The total phenolic content (B), the consumption of DPPH radical (C) and reducing power of hydroalcoholic extracts (D) is observed. Open circles represent means ( \pm standard error of the mean; $N=3$ ) of plants that underwent the UVB treatment and closed circles represent the control means ( \pm standard error of the mean; $N=3$ ). Significant differences between treatments are indicated by letters $\left({ }^{*} P<0.05\right)$.

Pereira et al., 2009). These processes involved SOD and POD enzymes and the secondary phenolic metabolites produced by the Antarctic hairgrass.

According to the results, $D$. antarctica showed efficient SOD and POD activities, complemented with a significant increase in antioxidant phenolics. SOD is known to be the enzyme that dismutates $\mathrm{O}_{2}{ }^{-}$to $\mathrm{H}_{2} \mathrm{O}_{2}$ and probably acts in a complex of antioxidant enzymes involved in signal transduction (Xia et al., 2015). On the other hand, $\mathrm{H}_{2} \mathrm{O}_{2}$ acts as a secondary messenger promoting antioxidative responses, i.e., increase of endogenous $\mathrm{H}_{2} \mathrm{O}_{2}$ is related to acclimation to stress in rice (Orozco-Cárdenas et al., 2001; Uchida et al., 2002).

Downstream from SOD action, $\mathrm{H}_{2} \mathrm{O}_{2}$ scavenging enzymes like class I PODs, such as APX, or class III PODs have different catalytic mechanisms (De Gara, 2004). Unlike APX, POD does not use ascorbate as a direct electron donor; however, POD has the property of oxidizing other molecules, especially natural phenolic compounds (De Gara, 2004). This, in addition to the increase in the total content of phenolic molecules, may explain the slight increase of APX activity compared to the high activity of POD. Class III PODs are found in various cellular compartments, including apoplasts, and have a wide range of isoforms, properties that allow POD to be rapidly activated by various stresses and highly efficient in the metabolism of $\mathrm{H}_{2} \mathrm{O}_{2}$. Furthermore, these enzymes are considered as an indicator of stress responses and might allow cellular responses to evaluate the intensity of an adverse environmental condition (Blokhina et al., 2003; Suzuki et al., 2012). Therefore, both SOD and POD playing important and effective roles in the enzymatic response of $D$. antarctica to high levels of UVBinduced ROS.

Enzymatic ROS scavenger mechanism is also complemented by a non-enzymatic antioxidant system response in $D$. antarctica, which is evident by the significant increases of total phenolics and bulk antioxidant activity after $3 \mathrm{~h}$ of exposure to UVB light. 
Some authors claim that the UVB tolerance of this plant is due to chemical properties these metabolites (Ruhland and Day, 2000; Xiong and Day, 2001). We showed a peak in total phenolic content of $D$. antarctica at $3 \mathrm{~h}$ of exposure, which related to percentage of consumed DPPH and FRAP values, suggesting that these phenolics function as soluble antioxidant metabolites. In terms of regulation, the PAL activity supports the hypothesis of de novo biosynthesis induced by UVB radiation in D. antarctica (Jaakola and Hohtola, 2010; Hideg et al., 2013). Thus, these secondary metabolites are not only important for their high antioxidant activity, but also for their photoprotective properties (Rozema et al., 2002; Winkel-Shirley, 2002; Pereira et al., 2009).

\section{CONCLUSION}

Our results suggest that (i) Deschampsia antarctica Desv. employs both enzymatic and non-enzymatic antioxidant systems that act as a whole to protect this Antarctic monocot against oxidative stress when exposed to natural daily fluctuations in UVB radiation ex vitro, (ii) the rapid activation of these mechanisms in this Antarctic hairgrass may explain its high tolerance to changes in UVB light in Antarctica. Our results support the hypothesis that antioxidant systems mediate the capacity of $D$. antarctica to survive in UVB enriched environments.

Further investigations need to focus on determining the role of antioxidant systems in the accumulative effect of UVB radiation in D. antarctica in field conditions.

\section{REFERENCES}

Beauchamp, C., and Fridovich, I. (1971). Superoxide dismutase: improved assays and an assay applicable to acrylamide gels. Anal. Biochem. 44, 276-287. doi: 10.1016/0003-2697(71)90370-8

Benzie, I. F. F., and Strain, J. J. (1999). Ferric reducing/antioxidant power assay: direct measure of total antioxidant activity of biological fluids and modified version for simultaneous measurement of total antioxidant power and ascorbic acid concentration. Methods Enzymol. 299, 15-27. doi: 10.1016/S0076-6879(99) 99005-5

Blokhina, O., Virolainen, E., and Fagerstedt, K. V. (2003). Antioxidants, oxidative damage and oxygen deprivation stress: a review. Ann. Bot. 91, 179-194. doi: $10.1093 / \mathrm{aob} / \mathrm{mcf1} 18$

Bradford, M. M. (1976). A rapid and sensitive method for the quantitation of microgram quantities of protein utilizing the principle of protein-dye binding. Anal. Biochem. 72, 248-254. doi: 10.1016/0003-2697(76)90527-3

Byun, M. Y., Lee, J., Cui, L. H., Kang, Y., Oh, T. K., Park, H., et al. (2015). Constitutive expression of DaCBF7, an Antarctic vascular plant Deschampsia antarctica $\mathrm{CBF}$ homolog, resulted in improved cold tolerance in transgenic rice plants. Plant Sci. 236, 61-74. doi: 10.1016/j.plantsci.2015.03.020

Chatterjee, A., and Kundu, S. (2015). Revisiting the chlorophyll biosynthesis pathway using genome scale metabolic model of Oryza sativa japonica. Sci. Rep. 5:14975. doi: 10.1038/srep14975

Contreras, R. A., Köhler, H., Pizarro, M., and Zúñiga, G. E. (2015). In vitro cultivars of Vaccinium corymbosum L. (Ericaceae) are a source of antioxidant phenolics. Antioxidants 4, 281-292. doi: 10.3390/antiox4020281

De Gara, L. (2004). Class III peroxidases and ascorbate metabolism in plants. Phytochem. Rev. 3, 195-205. doi: 10.1023/B:PHYT.0000047795.82713.99

Dixon, R. A., and Paiva, N. L. (1995). Stress-induced phenylpropanoid metabolism. Plant Cell 7, 1085-1097. doi: 10.1105/tpc.7.7.1085

\section{AUTHOR CONTRIBUTIONS}

HK designed and performed the experiments, and was the main contributor in writing the manuscript. RC designed and performed the experiments, produced the figures and performed the statistical analyses. MP and RC-A performed some experiments. GZ designed experiments, supervised all experiments and edited the manuscript.

\section{ACKNOWLEDGMENTS}

Thanks to the Ph.D. program in Biotechnology at the University of Santiago of Chile, the training program of advanced human capital of the National Commission for Scientific and Technological Research of Chile (CONICYT). Special thanks to the Chilean Antarctic Institute (INACH) that funded the DG01-12 project entitled: "Proteomic and metabolomic analysis of UV-B radiation tolerance in Deschampsia antarctica Desv. ex vitro." Authors would also like to specially acknowledge Elizabeth Barría and Rodolfo Parada for plant culture. This project was supported partially by FONDECYT-1140189 and Proyectos Basales USA1555 USACH-MECESUP (GZ).

\section{SUPPLEMENTARY MATERIAL}

The Supplementary Material for this article can be found online at: http://journal.frontiersin.org/article/10.3389/fpls.2017.00921/ full\#supplementary-material

Du, H., Liang, Y., Pei, K., and Ma, K. (2010). UV radiation-responsive proteins in rice leaves: a proteomic analysis. Plant Cell Physiol. 52, 306-316. doi: 10.1093/ $\mathrm{pcp} / \mathrm{pcq} 186$

Edelman, M., and Mattoo, A. K. (2008). D1-protein dynamics in photosystem II: the lingering enigma. Photosynth. Res. 98, 609-620. doi: 10.1007/s11120-0089342-x

Ederli, L., Reale, L., Ferranti, F., and Pasqualini, S. (2004). Responses induced by high concentration of cadmium in Phragmites australis roots. Physiol. Plant. 121, 66-74. doi: 10.1111/j.0031-9317.2004.00295.x

Foyer, C. H., and Noctor, G. (2005). Oxidant and antioxidant signalling in plants: a re-evaluation of the concept of oxidative stress in a physiological context. Plant Cell Environ. 28, 1056-1071. doi: 10.1111/j.1365-3040.2005. 01327.x

Frohnmeyer, H., and Staiger, D. (2003). Ultraviolet-B radiation-mediated responses in plants. Balancing damage and protection. Plant Physiol. 133, 1420-1428. doi: 10.1104/pp.103.030049

Heifetz, P. B., Lers, A., Turpin, D. H., Gillham, N. W., Boynton, J. E., and Osmond, C. B. (1997). $d r$ and $s p r / s r$ mutations of Chlamydomonas reinhardtii affecting D1 protein function and synthesis define two independent steps leading to chronic photoinhibition and confer differential fitness. Plant Cell Environ. 20, 1145-1157. doi: 10.1046/j.1365-3040.1997.d01-143.x

Hideg, É, Jansen, M. A. K., and Strid, Å. (2013). UVB exposure, ROS, and stress: inseparable companions or loosely linked associates? Trends Plant Sci. 18, 107-115. doi: 10.1016/j.tplants.2012.09.003

Hoagland, D. R., and Arnon, D. I. (1950). The water-culture method for growing plants without soil. California Agric. Exp. Stat. Circ. 347, 1-32.

Hyoungseok, L., Hyun Hee, C., Il-Chan, K., Joung Han, Y., Hong Kum, L., and Yoo Kyung, L. (2008). Expressed sequence tag analysis of antarctic hairgrass Deschampsia antarctica from king george island, antarctica. Mol. Cells 25, $258-264$. 
Jaakola, L., and Hohtola, A. (2010). Effect of latitude on flavonoid biosynthesis in plants. Plant Cell Environ. 33, 1239-1247. doi: 10.1111/j.1365-3040.2010. 02154.x

Jansen, M. A. K., Gaba, V., and Greenberg, B. M. (1998). Higher plants and UVB radiation: balancing damage, repair and acclimation. Trends Plant Sci. 3, 131-135. doi: 10.1016/S1360-1385(98)01215-1

Kalbin, G., Hidema, J., Brosché, M., Kumagai, T., Bornman, J. F., and Strid, Å. (2001). UVB-induced DNA damage and expression of defence genes under UVB stress: tissue-specific molecular marker analysis in leaves. Plant Cell Environ. 24, 983-990. doi: 10.1046/j.1365-3040.2001.00748.x

Kerr, J. B., and McElroy, C. T. (1993). Evidence for large upward trends of ultraviolet-B radiation linked to ozone depletion. Science 262, 1032-1034. doi: $10.1126 /$ science.262.5136.1032

Kochevar, I. E. (1990). UV-induced protein alterations and lipid oxidation in erythrocite membranes. Photochem. Photobiol. 52, 795-800. doi: 10.1111/j. 1751-1097.1990.tb08684.x

Kramarova, N. A., Nash, E. R., Newman, P. A., Bhartia, P. K., McPeters, R. D., Rault, D., et al. (2014). Measuring the antarctic ozone hole with the new ozone mapping and profiler suite (OMPS). Atmos. Chem. Phys. 14, 2353-2361. doi: 10.5194/acp-14-2353-2014

Lichtenthaler, H. K., and Wellburn, A. R. (1983). Determinations of total carotenoids and chlorophylls a and b of leaf extracts in different solvents. Biochem. Soc. Trans. 11, 591-592. doi: 10.1042/bst0110591

Lima, A. L. S., DaMatta, F. M., Pinheiro, H. A., Totola, M. R., and Loureiro, M. E. (2002). Photochemical responses and oxidative stress in two clones of Coffea canephora under water deficit conditions. Environ. Exp. Bot. 47, 239-247. doi: 10.1016/S0098-8472(01)00130-7

Liu, X., Yue, M., Ji, Q., and He, J. (2013). "Effects of ultraviolet-B radiation on primary photophysical process in photosystem II: a fluorescence spectrum analysis," in Proceedings of the 15th International Conference on Photosynthesis Photosynthesis Research for Food, Fuel and the Future (Berlin: Springer), 642-649. doi: 10.1007/978-3-642-32034-7_140

Mittler, R. (2002). Oxidative stress, antioxidants and stress tolerance. Trends Plant Sci. 7, 405-410. doi: 10.1016/S1360-1385(02)02312-9

Müller-Xing, R., Xing, Q., and Goodrich, J. (2014). Footprints of the sun: memory of UV and light stress in plants. Front. Plant Sci. 5:474. doi: 10.3389/fpls.2014. 00474

Naik, G. H., Priyadarsini, K. I., and Mohan, H. (2005). Evaluating the antioxidant activity of different plant extracts and herbal formulations. Res. Chem. Intermed. 31, 145-151. doi: 10.1163/1568567053146823

Orozco-Cárdenas, M. L., Narváez-Vásquez, J., and Ryan, C. A. (2001). Hydrogen peroxide acts as a second messenger for the induction of defense genes in tomato plants in response to wounding, systemin, and methyl jasmonate. Plant Cell 13, 179-192. doi: 10.1105/tpc.13.1.179

Pang, Q., and Hays, J. B. (1991). UVB-Inducible and temperature-sensitive photoreactivation of cyclobutane pyrimidine dimers in Arabidopsis thaliana. Plant Physiol. 95, 536-543. doi: 10.1104/pp.95.2.536

Pellegrini, L., Rohfritsch, O., Fritig, B., and Legrand, M. (1994). Phenylalanine ammonia-lyase in tobacco (molecular cloning and gene expression during the hypersensitive reaction to tobacco mosaic virus and the response to a fungal elicitor). Plant Physiol. 106, 877-886. doi: 10.1104/pp. 106.3.877

Pereira, B. K., Rosa, R. M., Silva, J. D., Guecheva, T. N., Oliveira, I. M. D., Ianistcki, M., et al. (2009). Protective effects of three extracts from Antarctic plants against ultraviolet radiation in several biological models. J. Photochem. Photobiol. Biol. 96, 117-129. doi: 10.1016/j.jphotobiol.2009. 04.011

Pérez-Torres, E., Bravo, L. A., Corcuera, L. J., and Johnson, G. N. (2007). Is electron transport to oxygen an important mechanism in photoprotection? Contrasting responses from Antarctic vascular plants. Physiol. Plant. 130, 185-194. doi: 10.1111/j.1399-3054.2007.00899.x

Petersen, M., Hans, J., and Matern, U. (2010). "Biosynthesis of phenylpropanoids and related compounds," in Annual Plant Reviews: Biochemistry of Plant Secondary Metabolism, Vol. 40, ed. M. Wink (Hoboken, NJ: Wiley-Blackwell), 182-257. doi: 10.1002/9781444320503.ch4

Rao, M. V., Paliyath, G., and Ormrod, D. P. (1996). Ultraviolet-B- and ozoneinduced biochemical changes in antioxidant enzymes of Arabidopsis thaliana. Plant Physiol. 110, 125-136. doi: 10.1104/pp.110.1.125
Robinson, S. A., Wasley, J., and Tobin, A. K. (2003). Living on the edge plants and global change in continental and maritime Antarctica. Glob. Change Biol. 9, 1681-1717. doi: 10.1046/j.1365-2486.2003. 00693.x

Robson, T. M., Klem, K., Urban, O., and Jansen, M. A. K. (2015). Re-interpreting plant morphological responses to UVB radiation. Plant Cell Environ. 38, 856-866. doi: 10.1111/pce. 12374

Ross, C., Puglisi, M. P., and Paul, V. J. (2008). Antifungal defenses of seagrasses from the Indian River Lagoon, Florida. Aquat. Botany 88, 134-141. doi: 10. 1016/j.aquabot.2007.09.003

Rousseaux, M. C., Ballaré, C. L., Giordano, C. V., Scopel, A. L., Zima, A. M., Szwarcberg-Bracchitta, M., et al. (1999). Ozone depletion and UVB radiation: impact on plant DNA damage in southern South America. Proc. Natl. Acad. Sci. U.S.A. 96, 15310-15315. doi: 10.1073/pnas.96.26. 15310

Rousseaux, M. C., Flint, S. D., Searles, P. S., and Caldwell, M. M. (2004) Plant responses to current solar ultraviolet-B radiation and to supplemented solar ultraviolet-b radiation simulating ozone depletion: an experimental comparison. Photochem. Photobiol. 80, 224-230. doi: 10.1111/j.1751-1097.2004. tb00075.x

Rozema, J., Björn, L. O., Bornman, J. F., Gaberšèik, A., Häder, D. P., Trošt, T., et al. (2002). The role of UVB radiation in aquatic and terrestrial ecosystemsan experimental and functional analysis of the evolution of UV-absorbing compounds. J. Photochem. Photobiol. Biol. 66, 2-12. doi: 10.1016/S10111344(01)00269-X

Ruhland, C. T., and Day, T. A. (2000). Effects of ultraviolet-B radiation on leaf elongation, production and phenylpropanoid concentrations of Deschampsia antarctica and Colobanthus quitensis in Antarctica. Physiol. Plant. 109, 244-251. doi: 10.1034/j.1399-3054.2000.100304.x

Ruhland, C. T., Xiong, F. S., Clark, W. D., and Day, T. A. (2005). The Influence of ultraviolet-B radiation on growth, hydroxycinnamic acids and flavonoids of Deschampsia antarctica during springtime ozone depletion in antarctica. Photochem. Photobiol. 81, 1086-1093. doi: 10.1562/2004-0918-RA-321

Sancar, A., and Sancar, G. B. (1988). DNA repair enzymes. Annu. Rev. Biochem. 57, 29-67. doi: 10.1146/annurev.bi.57.070188.000333

Sequeida, Á., Tapia, E., Ortega, M., Zamora, P., Castro, Á., Montes, C., et al. (2012). Production of phenolic metabolites by Deschampsia antarctica shoots using UVB treatments during cultivation in a photobioreactor. Electron. J. Biotechnol. 15:7. doi: 10.2225/vol15-issue4-fulltext-7

Shanklin, J. (2010). Reflections on the ozone hole. Nature 465, 34-35. doi: 10.1038/ $465034 \mathrm{a}$

Smith, H. (1990). Signal perception, differential expression within multigene families and the molecular basis of phenotypic plasticity. Plant Cell Environ. 13, 585-594. doi: 10.1111/j.1365-3040.1990.tb01077.x

Solomon, S. (2004). The hole truth. Nature 427, 289-291. doi: 10.1038/427289a

Solomon, S., Ivy, D. J., Kinnison, D., Mills, M. J., Neely, R. R., and Schmidt, A. (2016). Emergence of healing in the Antarctic ozone layer. Science 353, 269-274. doi: 10.1126/science.aae0061

Suzuki, N., Koussevitzky, S., Mittler, R. O. N., and Miller, G. A. D. (2012). ROS and redox signalling in the response of plants to abiotic stress. Plant Cell Environ. 35, 259-270. doi: 10.1111/j.1365-3040.2011. 02336.x

Teramura, A. H., and Sullivan, J. H. (1994). Effects of UVB radiation on photosynthesis and growth of terrestrial plants. Photosynth. Res. 39, 463-473. doi: 10.1007/BF00014599

Teramura, A. H., Sullivan, J. H., and Lydon, J. (1990). Effects of UVB radiation on soybean yield and seed quality: a 6-year field study. Physiol. Plant. 80, 5-11. doi: 10.1111/j.1399-3054.1990.tb04367.x

Tevini, M., and Steinmüller, D. (1987). Influence of light, UVB radiation, and herbicides on wax biosynthesis of cucumber seedling. J. Plant Physiol. 131, 111-121. doi: 10.1016/S0176-1617(87)80272-9

Tevini, M., and Teramura, A. H. (1989). UVB effects on terrestrial plants. Photochem. Photobiol. 50, 479-487. doi: 10.1111/j.1751-1097.1989. tb05552.x

Tognetti, V. B., Mühlenbock, P. E. R., and Van Breusegem, F. (2012). Stress homeostasis - the redox and auxin perspective. Plant Cell Environ. 35, 321-333. doi: 10.1111/j.1365-3040.2011.02324.x 
Uchida, A., Jagendorf, A. T., Hibino, T., Takabe, T., and Takabe, T. (2002). Effects of hydrogen peroxide and nitric oxide on both salt and heat stress tolerance in rice. Plant Sci. 163, 515-523. doi: 10.1016/S0168-9452(02)00159-0

van de Staaij, J., de Bakker, N. V. J., Oosthoek, A., Broekman, R., van Beem, A., Stroetenga, M., et al. (2002). Flavonoid concentrations in three grass species and a sedge grown in the field and under controlled environment conditions in response to enhanced UVB radiation. J. Photochem. Photobiol. Biol. 66, 21-29. doi: 10.1016/S1011-1344(01)00271-8

Vass, I., Szilárd, A., and Sicora, C. (2005). “Chapter 43: adverse effects of UVB light on the structure and function of the photosynthetic apparatus," in Handbook of Photosynthesis, 2nd Edn, ed. M. Pessarakli (Boca Raton, FL: CRC press), 931-949.

Von Wettstein, D., Gough, S., and Kannangara, C. G. (1995). Chlorophyll biosynthesis. Plant Cell 7, 1039-1057. doi: 10.1105/tpc.7.7.1039

Winkel-Shirley, B. (2002). Biosynthesis of flavonoids and effects of stress. Curr. Opin. Plant Biol. 5, 218-223. doi: 10.1016/S1369-5266(02)00256-X

Xia, X.-J., Zhou, Y.-H., Shi, K., Zhou, J., Foyer, C. H., and Yu, J.-Q. (2015). Interplay between reactive oxygen species and hormones in the control of plant development and stress tolerance. J. Exp. Bot. 66, 2839-2856. doi: 10.1093/jxb/ erv089
Xiong, F. S., and Day, T. A. (2001). Effect of solar ultraviolet-B radiation during springtime ozone depletion on photosynthesis and biomass production of antarctic vascular plants. Plant Physiol. 125, 738-751. doi: 10.1104/pp. 125.2.738

Zamora, P., Rasmussen, S., Pardo, A., Prieto, H., and Zúñiga, G. E. (2010). Antioxidant responses of in vitro shoots of Deschampsia antarctica to Polyethylene glycol treatment. Antarct. Sci. 22, 163-169. doi: 10.1017/ S0954102009990733

Conflict of Interest Statement: The authors declare that the research was conducted in the absence of any commercial or financial relationships that could be construed as a potential conflict of interest.

Copyright (C) 2017 Köhler, Contreras, Pizarro, Cortés-Antíquera and Zúñiga. This is an open-access article distributed under the terms of the Creative Commons Attribution License (CC BY). The use, distribution or reproduction in other forums is permitted, provided the original author(s) or licensor are credited and that the original publication in this journal is cited, in accordance with accepted academic practice. No use, distribution or reproduction is permitted which does not comply with these terms. 